\title{
Spontaneous Splenic Rupture in Sickle Cell Disease: Rare Case in Adults and First Recorded in South America
}

\author{
Madani Galleze ${ }^{1}$, Hatem Kallel ${ }^{2}$, Hajer Kraiem¹, Majdi Omri', Didier Hommel ${ }^{2}$, Hakim Amroun ${ }^{3}$, \\ Jean Marc Pujo ${ }^{1}$
}

${ }^{1}$ Emergency Department, ${ }^{2}$ Intensive Care Unit, ${ }^{3}$ Surgery Department; Cayenne General Hospital, Cayenne, French Guiana.

\section{Corresponding Author: \\ Dr Jean Marc Pujo \\ Email : tamac66@gmail.com}

This is an Open Access article distributed under the terms of the Creative Commons Attribution License (creativecommons.org) licenses/by/3.0).

Received : July 2, 2020

Accepted : January 19, 2021

Published : March 15, 2021

\begin{abstract}
Background: We report a case of spontaneous splenic rupture in a 27-year-old man with a known history of SS homozygous sickle cell disease. Case Report: The patient presented for increasing left basithoracic pain evolving for 4 days of spontaneous onset and signs of hypovolemia. The CT scan showed an intra-peritoneal effusion, an enlarged and heterogenous spleen, associated with perisplenic subcapsular hematoma, without parenchymal lacerations or active bleeding. The diagnosis of spontaneous spleen rupture in the context of homozygous SS sickle cell anemia was finally retained and we decided to monitor the patient in intensive care unit without surgery. No complication occurred during the patient's stay and he left the hospital three weeks after admission. Conclusion: Conservative treatment is a multidisciplinary decision that will require close monitoring in intensive care unit.
\end{abstract}

Keywords: Hematoma, Intensive Care Units, Lacerations, Sickle Cell Anemia, Splenic Rupture.

\section{Introduction}

Sickle cell disease is a genetic hemoglobin disorder due to inheritance of mutant hemoglobin genes from both, generally healthy, parents and affects millions worldwide. The latter is considered as a public health priority in French overseas territories mainly in French Guiana which is the French territory the most affected by this disease. Spleen rupture principally caused by a traumatism and spontaneous ruptured spleen on sickle cell disease is rarely described in the scientific literature [1]. We report a case of spontaneous splenic rupture in a patient with sickle cell disease

\section{Case Report}

A 27-year-old man with a known history of SS homozygous sickle cell disease presented to the emergency department (ED) of Cayenne for left basithoracic pain evolving for 4 days of spontaneous onset, no irradiation (mainly to the left shoulder) and increasing for 36 hours. The first thorough interrogation did not reveal any recent traumatic or infectious context. Upon arrival at the ED, vital parameters showed a blood pressure $107 / 87 \mathrm{mmHg}$ with regular tachycardia at 127 beats/ min, breath rhythm 22 breaths/ min, oxygen saturation $92 \%$ despite $5 \mathrm{~L} / \mathrm{min}$ and the hemoglobin at $7 \mathrm{~g} / \mathrm{dL}$, temperature $97.6 \mathrm{~F}$. A quick clinical assessment found a painful abdomen with localized defense on palpation of the left hypochondrium associated with splenomegaly while the remaining examination was normal. The e-FAST ultrasound showed a free intra-peritoneal effusion, an enlarged and heterogenous spleen, and peri-splenic collection as well as a low abundance of left pleural effusion suggesting hemorrhage secondary to splenic rupture. After initial care, the patient was sent to the radiology department for further assessment. The CT scan showed an intra- 
peritoneal effusion, an enlarged and heterogenous spleen, associated with a peri-splenic subcapsular hematoma, without parenchymal lacerations or active bleeding [Fig.1]. The patient was ranked grade III (Buntain and Barret classification) and score 4 (Resciniti classification).

The initial lab analysis showed anemia at $6.5 \mathrm{~g} / \mathrm{dL}$ (for an usual dosage at $9.7 \mathrm{~g} / \mathrm{dL}$ ) with an average red cell volume at $65 \mathrm{fL}$ and a hematocrit at $36 \%$. The platelets count was $52 \mathrm{Giga} / \mathrm{L}$, the prothrombin and activated cephalin time dosages were normal, no biological markers evoking an infection or inflammatory process, the rest of the biological assessment was without any other particularity mainly for which concerns usual causes of atraumatic rupture such as viral, bacterial, parasitic as well as malignant hemopathy.

The diagnosis of spontaneous spleen rupture in the context of homozygous SS sickle cell anemia was finally retained. After surgical advice, it was decided to monitor the patient in intensive care unit (ICU). During ICU stay, the hemodynamic condition of the patient was stable and he did not require blood cell transfusion. The second CT scan highlights a laceration of the anterior edge unnoticed in the first examination [Fig.2]. No complication occurred during the patient's stay and he left the hospital three weeks after admission with analgesic, vitamin treatment including folic acid, antibiotic prophylaxis, and anti-pneumococcal and anti-meningococcal vaccination.

\section{Discussion}

In French Guiana, over 2000 cases of sickle cell disease are identified (heterozygous and homozygous included) with a prevalence of 145 cases/100,000 inhabitants. The incidence of major sickle cell syndromes at birth is $1 / 227$ and frequency of carriers of sickle cell trait is $5.2 \%$. Sickle cell anemia is reported in the scientific literature among the benign hemopathies and a rare cause of spontaneous rupture of spleen [1].

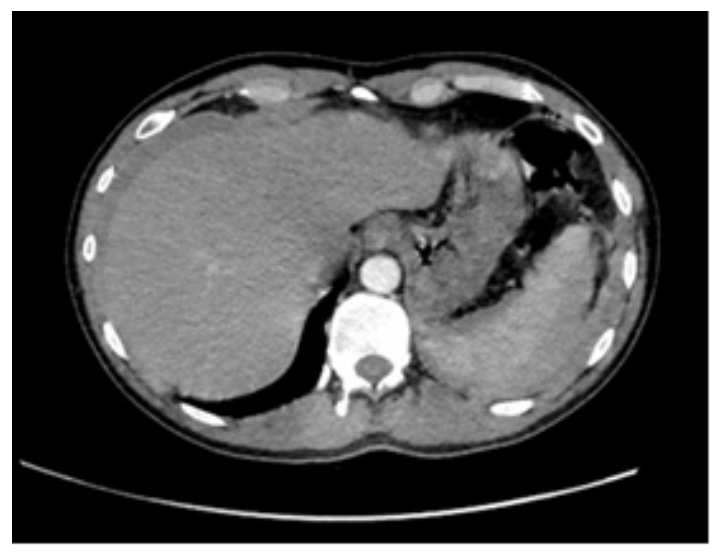

Fig.1: Abdominal CT scan at admission.

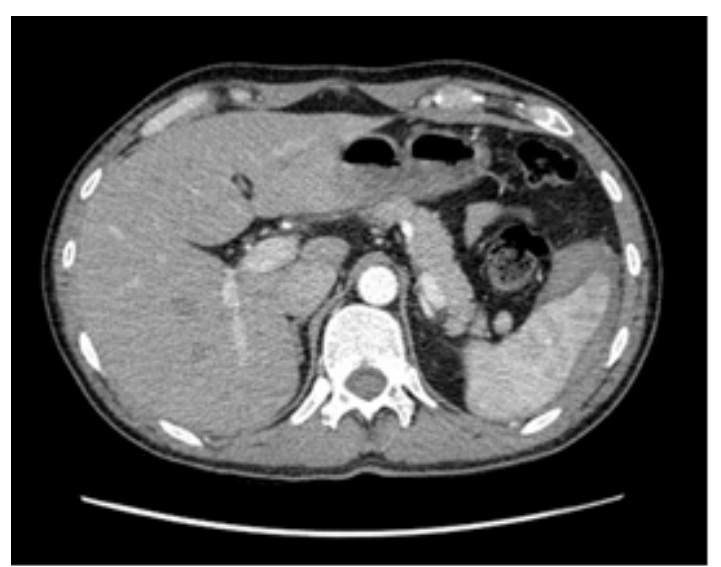

Fig.2: $C T$ scan few days after showing net increase in hematoma.

Non-traumatic splenic ruptures are principally due to diseases with splenic tropism such as infectious pathologies that might be viral (Epstein Barr Virus), bacterial or parasitic (malaria) as well as benign or malignant hemopathies, solid or cystic tumors, digestive diseases like pancreatitis or other various such as rheumatoid purpura, lupus, post-partum or renal failure with dialysis, anticoagulation or fibrinolytic treatment and others [2]. In this patient, after ruling out a recent traumatism and all other causes of spleen rupture, we retained the diagnosis of spontaneous spleen rupture linked to the sickle cell disease. In the best of our knowledge, only few cases of spontaneous ruptured spleen in adult sickle cell patients have been reported [2-5]. Several pathophysiological 
mechanisms have been discussed, which alone or combined might be responsible for splenic rupture. Among them, mechanical distension, congestion of splenic tissue by blastic infiltration, coagulation issue and splenic infarction were reported [1]. In this case, the low level of platelets, for which we didn't investigate the etiopathogenesis, has certainly influenced the bleeding. It is usual to say that the rupture of spleen can occur in two stages with at first the formation of a subcapsular hematoma then in a second time the capsular rupture. In absence of recent traumatism context, the main risk is to not evoke immediately the diagnosis of spontaneous rupture and lose time which can be precious in the initial care of the patient. Mortality associated with delayed spleen rupture diagnosis is important [6]. In the present case, several factors raised the diagnose of splenic rupture. First at all, the patient was known as sickle cell disease carrier which is a well-known disease in French Guiana. Second, e-FAST USG, a routine examination in emergency situations, was helpful to make quickly the diagnosis. It is noteworthy that Kehr's sign which is a projected pain in the left shoulder resulting from a homolateral sub-diaphragmatic irritation could have helped the diagnosis but was absent in this patient [7].

Sickle cell patients live usually with a chronic anemia reaching a hemoglobin range around 7-8 g/dL and usually it doesn't need blood transfusion at this stage (usual level for this patient was $9.7 \mathrm{~g} / \mathrm{dL}$ ). In other words, those sickle cell patients can maintain at low hemoglobin rate without any hemodynamic impact. Our patient presented with signs of hypovolemia with pinched blood pressure associated with tachycardia. His hemoglobin level should therefore not be considered falsely reassuring but rather as an indicator of active bleeding. After emergency management the patient was deemed sufficiently stable to undergo CT scan with contrast administration which is a key examination to discuss abstention from surgery but should not delay it. The patient was ranked grade
III (Buntain and Barret classification) and score 4 (Resciniti classification) [8]. Despite the patient's rank borderline, the decision to not send the patient to the surgery room has been made. The patient recovered well under intensive care and close monitoring.

\section{Conclusion}

The spontaneous rupture of the spleen is rare and difficult to diagnose. The practitioner in charge of a sickle cell patient with left flank pain should keep in mind this diagnostic hypothesis. The abdominal CT scan is fundamental to detect splenic lesions, especially if the clinical presentation is confusing or does not clearly demonstrate its etiology. The other causes of non-traumatic splenic rupture must be systematically considered, especially neoplastic, infectious and inflammatory. Conservative treatment is a multidisciplinary decision that will require close monitoring in intensive care unit. Notwithstanding, a first-line surgical approach is recommended in case of hemodynamic failure despite an adequate initial resuscitation.

Contributors: MG, HKr: Patient management and préparation of draft manuscript; $\mathrm{HKa}, \mathrm{MO}, \mathrm{DH}$ : patient management and manuscript revision; HA, JMP : patient management and critical inputs into the manuscript. JMP acted as study guarantor. All authors approved the final version of the manuscript and are responsible for all aspects of the study.

Funding: None; Competing interests: None stated.

\section{References}

1. Franck L, Dutasta F, Bensalah M, Daban JL, Clapson P, Poirier $\mathrm{H}$, et al. Rupture spontanée de rate: un diagnostic différentiel d'abdomen aigu. Réanimation. 2011;20:572573.

2. Kianmanesh R, Aguirre HI, Enjaume F, Valverde A, Brugière $\mathrm{O}$, Vacher $\mathrm{B}$, et al. Spontaneous splenic rupture: report of three new cases and review of the literature. Ann Chir. 2003;128:303-309.

3. Arora MM, Bhatia JK, Khanna V, Jaiswal P, Charan VD. Splenic syndrome due to Sickle cell trait amongst Indian soldiers serving in Kashmir. Med J Armed Forces India. 2008;64:123-126.

4. Aubrey-Bassler FK, Sowers N. 613 cases of splenic rupture without risk factors or previously diagnosed disease: a systematic review. BMC Emerg Med. 2012;12:11. 
5. Sharma D. Sub capsular splenectomy for delayed spontaneous splenic rupture in a case of sickle cell anemia. World J Emerg Surg. 2009;4:17.

6. Sowers N, Aubrey-Bassler FK. Trivial trauma and delayed rupture of a normal spleen: a case report. J Med Case Reports. 2011;5:591.
7. Slimani H, Hugonnot S, Sengler L. Signe de Kehr. Un signe clinique qui peut sauver! Ann Fr Médecine D'urgence. 2017;7:205.

8. Duverger V, Muller L, Szymszyczyn P, Vergos M. Surgical abstention in closed injuries of the spleen. Ann Chir. 2000;125:380-384. 